\title{
Entrepreneurial development in South Africa through innovation: A model for poverty alleviation
}

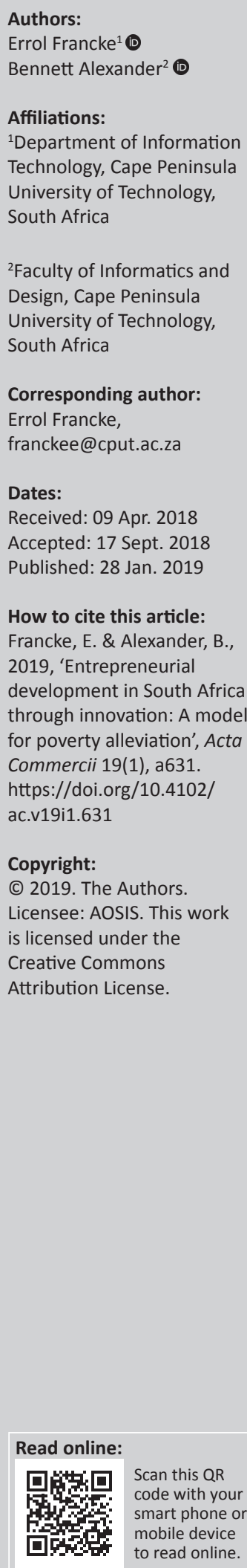

Orientation: The development agency could be equipped with a model that will assist them in supporting mobile application development entrepreneurs towards enhanced competitiveness that could assist in alleviating poverty and reducing economic inequality.

Research purpose: The purpose of this study is to explore the evolution of a model to support mobile application development entrepreneurs towards enhanced competitiveness.

Motivation for the study: This study was motivated by the views on black economic empowerment where little has been done to impact the lives of black people on a larger scale. Broader participation of black people in the formal economy is required to achieve sustainable development and prosperity. Studies suggest that innovation through technology transfer is regarded as a contributor to economic growth.

Research design, approach and method: This study adopted the Critical Realist Methodology Model via an inductive research approach. Focused interviews with academics, small and medium-sized enterprises in the innovation and technology industry and development agencies were conducted.

Main findings: There is business potential in mobile applications, but entrepreneurs have difficulty in commercialising these. They could be assisted with a model that would transform their applications into real business opportunities.

Practical/managerial implications: The antidote to disruptive innovation is a management response. What is required from management is that it needs to bring about a paradigm shift in the way that the whole notion of a business is remodelled.

Contribution/value-add: This study reveals a multi-factorial strategy model in the form of the Disruptive Innovation State Response Model that could support mobile application development entrepreneurs towards enhanced competitiveness.

\section{Introduction}

This study was motivated by the views on black economic empowerment of Naidoo (2002) in which the author states that very little has been done to positively impact the lives of black people on a larger scale. The author suggests that to truly effect this change, initiatives including job creation, poverty alleviation and access to business finance must be prioritised.

The views of Naidoo (2002) are supported by the Institute of Directors in Southern Africa (2002) in their King II report on corporate governance in South Africa (SA). The report proposes that black economic empowerment should be aimed at redressing the continued unequal distribution of ownership, management and control of SA's financial and economic resources. It could be achieved by ensuring broader participation of black people in the formal economy to achieve sustainable development and prosperity. In a further report, the Institute of Directors in Southern Africa (2016) suggests that there are profound disruptions to industries and business models. Their King IV report proposes that business models should positively impact on society and the environment, and in this way the quality of life in countries such as SA should improve.

Nearly 3 decades ago, Krugman (1994) stated that SA was part of a truly global economy. In a post-politically reformed SA which now allowed for international trade, SA had to learn to compete in a competitive world marketplace. In this world, higher productivity and product quality were indispensable. The author suggests that the SA economy had to move into highvalue sectors that would generate jobs for the future. To ensure competitiveness, partnerships between the SA government and business had to be forged. 
Dishearteningly, the Organisation for Economic Co-operation and Development (2017) recently released its economic survey relating to the economic outlook of SA. It suggests that the unemployment rate has increased from $25 \%$ to $27 \%$ because of economic slowdown and income inequalities remain wide between the rich and the poor. The survey proposes that entrepreneurship is vital to increase job creation. Entrepreneurship in SA is low in comparison with other emerging economies. This could be improved with government policies supported by financial and non-financial backing. In particular, the youth have an unemployment rate of $53 \%$. The quality of the education system and lack of work experience contribute to gaps in entrepreneurial skills.

Gartner (2014) predicts that the magnitude of mobile applications implies that mobile is a new revenue stream that could benefit many mobile application development small and medium-sized enterprises (SMEs); however, less than $0.01 \%$ of consumer mobile applications will be considered a financial success by their developers and most mobile applications are not generating profits. Mobile app development SMEs that do not give thought to this may find profits elusive.

With respect to the African adoption of mobile phones, Bankole and Bankole (2017) claim that information communication technology innovation is one of the major forces in socioeconomic development. They regard this innovation as a significant component in spurring growth in a country's economy. Encouraged by the proliferation of mobile phones, they observe the effect of sociocultural factors on mobile banking services in South Africa.

Based on the understanding that black economic empowerment has led to insignificant impact on the lives of black people as a whole, this study suggests that initiatives including job creation, poverty alleviation and access to business finance must be prioritised. Broader participation of black people in the formal economy, particularly in the mobile application development industry, is required to achieve sustainable development and prosperity.

This study shall explore the evolution of a model to support mobile application development entrepreneurs towards enhanced competitiveness that could assist in alleviating poverty and reducing economic inequality.

\section{Literature review}

The purpose of this literature review was to establish an integrated platform for the key tenets of the research. Consequently, the objectives were to establish the dimensions of business model innovation that might inform the research proposition, establish the relationships between the key tenets of the research and, finally, to establish a framework linking business model innovation and disruptive innovation based on a critical realist underpinning. The literature review would attempt to evolve the logic justified in the context of the research by creating an understanding of the extant body of knowledge. It would not attempt to portray the literature as procedural links between elements within it because the disciplines covered in this review were wide and the literature was deep.

Initial enquiry into this study suggested that an investigation should be conducted into discrete themes such as mobile applications as an instance of innovation; business models that best support mobile application development; the state and value of entrepreneurs to the SA economy; and government support that could be rendered to assist these entrepreneurs.

This study, therefore, responds to reports of the proliferation of disruptive innovation from Gartner (2008) and years later from other studies that suggested that the mobile applications industry had experienced unprecedented growth (Rakestraw, Eunni \& Kasuganti 2013). Rowlands (2013), in a report by Juniper Research, predicted that in 2017 over 160 billion applications would be downloaded globally onto consumer handsets and tablets.

Research around innovation in business models is supported by ideas of 'business model ontology' of Osterwalder (2004:3), 'the evolving business model concept' of Ammar and Ouakouak (2015:80), as well as the contention of Díaz-Díaz, Muñoz \& Pérez-González (2017) who state that many organisations of various industries are trying different combinations of business models, yet there are inadequate studies that focus on business models and business model innovation.

Although innovation ordinarily manifests in a new product or service, business model innovation results in a completely different type of business that competes not only on the value proposition of its offerings, but aligns its profit formula, resources and processes to enhance that value proposition, capture new market segments and alienate competitors (Francke \& Alexander 2012). Baden-Fuller and Haefliger (2013) argue that business models are fundamentally linked with technological innovation, yet the paradigm of the business model is fundamentally discrete from technology. Theories of strategic management are postulated by Porter $(1990,1998,2001)$ in which the author constantly illustrates the importance of a business remaining competitive. Porter (2001) warns that if a business views the business model in isolation from its strategy, it may hinder the business's most important advantages. The author further contends that a business must continue innovating as it is constantly exposed to new competitors and substitute products. It is, therefore, prudent for business owners to consider the various propositions around business models and the value of innovating them. Business model innovation could be regarded as the rejuvenation of a business's system of identifying who its customers are, how to engage with their needs, how to deliver satisfaction and how to monetise the value. 
In congruence with the views of Porter, the Theory of Diffusion of Innovation as postulated by Rogers (2003) expounds how, why and at what rate new ideas and technology spread through cultures and the way that they are communicated via channels over time among the participants in a social system. This theory has relevance to this study by virtue of the fact that entrepreneurs should consider that adoption of their innovation does not only rely on the innovation's technical capabilities. The entrepreneurs would have to consider how their business model relates to the segment of the market to which its innovation is appealing.

In recognition of Krugman (1994) and SBP (2011) in their discussion of the SME Growth Index, SA's finance minister has declared that SMEs are critical to overall employment and job creation. The truth, however, is that the SA economy is shedding jobs, and those that are being created are disproportionately in the public sector. The report further suggests that the solution lies in entrepreneurship and small business. However, a subsequent report, SBP (2015), warns that SMEs in SA indicate a decrease in employment and the bulk are struggling to survive. This contrasts with international trends where SMEs are the largest employers in either developed or developing economies.

The efforts to expand the number of small businesses need to be located within an understanding of the nature of businesses that the economy can best support (SBP 2011). This view is supported by the theory of entrepreneurship as proposed by Schumpeter (1947) who argued that the innovation and technological change of a nation come from entrepreneurs. The theory suggests that the act of doing new things emanates directly from the free-spirited efforts of entrepreneurs. Schumpeter (1947) defines entrepreneurship from the economics perspective by focusing on the perception of new economic opportunities and the subsequent introduction of new ideas in the market.

Le Roux (2010) suggests that the partnership between government and business as proposed by Krugman (1994) can be achieved through development agencies. These are agencies that aim to assist, advance and support growth within a region through the provision of resources and assistance, usually from state organisations. The enterprise development strategy must ensure the viability of the business idea which should lead to the creation of new business value.

Mandel (2012) suggests that government's potential solution to boosting employment lies in innovation. A particular aspect of this is disruptive innovation, which causes major change to the way in which industries operate. The term 'disruptive innovation' was defined and its phenomenon was analysed by Bower and Christensen (1995). It calls for innovation not only at the technological level but also at the business level. In this way, new goods and services are created, giving rise to new industries through which employment is created. A prime example of this is the rise of a disruptive innovation like mobile applications that could provide jobs for developers, designers, marketers and other related staff. In the vein of Krugman (1994), who proposes that government forges better ties with business, this mobile application economy can be facilitated by development agencies.

This study considers the challenges facing SMEs identified by Robson and Bennett (2000), Olawale and Garwe (2010), SBP (2011), Neneh and Van Zyl (2014) and SBP (2015), and responds to the potential of the mobile application economy. It contends that businesses might have to implement business model innovation which refers to the creation, or reinvention, of a business itself. This study proposes that a multi-factorial strategy model can be evolved to enable development agency to be an augmenter in the commercialisation of the mobile applications development SME sector through business model innovation in response to disruptive innovation.

The literature deals incompletely with the fact that the dimension of business model innovation is the creation of substantial new value for the business and the achievement of commercial viability. The literature further incommensurately deals with the fact that the nature of innovation is not only at the technological but also at the business level. Lastly, the literature inadequately deals with the fact that the potential role of the development agency is to provide strategic support, capacity building and mechanisms for growth and sustainability.

Given the gaps in the extant literature, this study interrogates the proliferation of disruptive innovation and unprecedented growth of mobile applications. It seems to suggest that the proliferation of mobile applications could present an opportunity to entrepreneurs in the mobile application development industry. In this way, the mobile application development industry could potentially play a significant role in the development of the SA economy by creating jobs. However, other than innovation of product, entrepreneurs in this industry would have to gear their business models to take advantage of the innovation in the mobile application industry. These entrepreneurs are, however, challenged like many other entrepreneurs, and they would need support from government to ensure success and sustainability. It appears, therefore, that these entrepreneurs would benefit from a model that will assist towards enhanced competitiveness and ultimately in alleviating poverty and reducing economic inequality.

\section{Research methodology Research design}

This study is motivated by the plight to alleviate poverty and reduce economic inequality (Figure 1). It resolves to prove that a multi-factorial strategy model can be evolved to enable development agency to be an augmenter in the commercialisation of the mobile applications development SME sector through business model innovation in response 


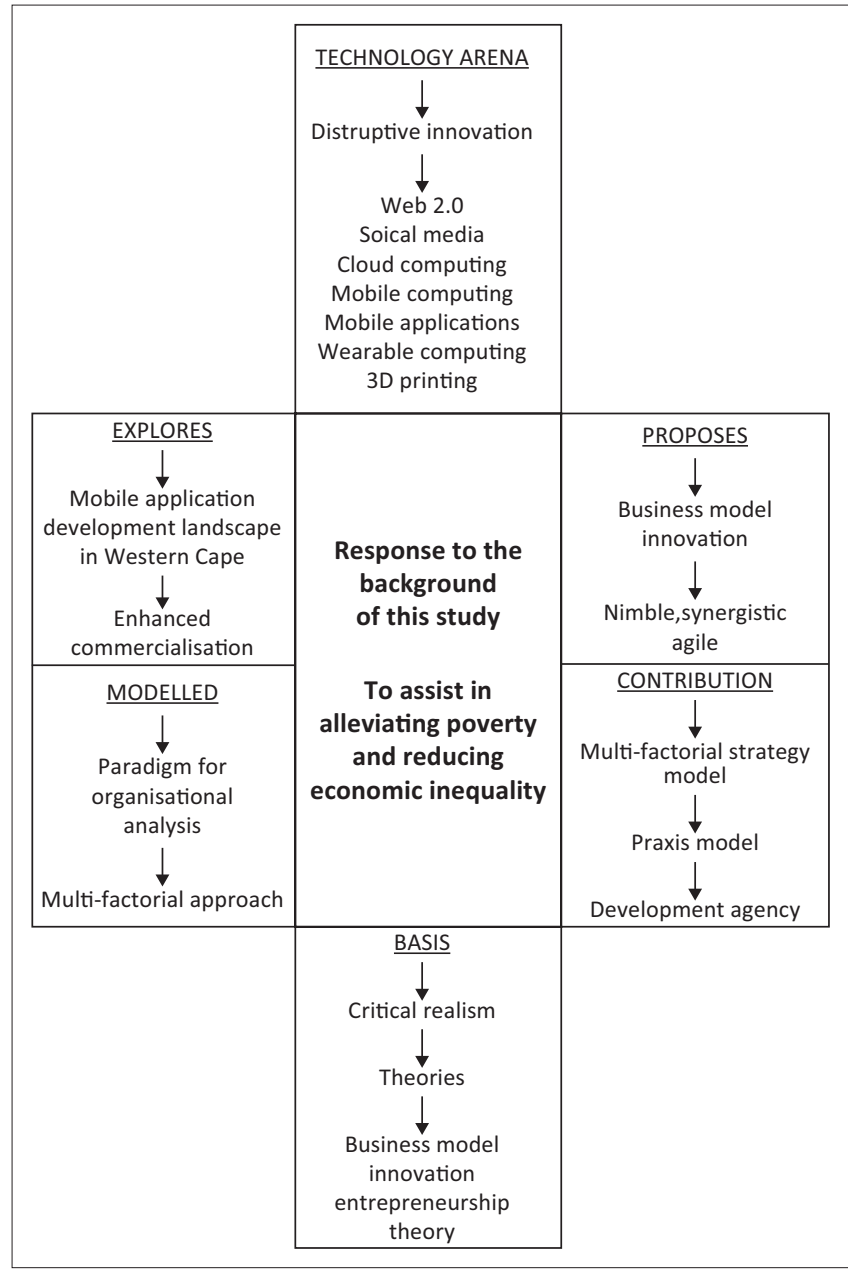

FIGURE 1: A graphical representation of the research design of this study.

to disruptive innovation. The golden thread of this study is the journey to uncover three tenets:

- the dimensions of business model innovation;

- the nature of disruption; and

- the potential role of the development agency in supporting entrepreneurs in the innovation and technology industry.

\section{Research approach of the study}

Research studies draw attention to the proliferation of mobile applications as a case of disruptive innovation over recent years. Of significance is not only the technical aspects and functionality of the mobile applications but also the business models. There are low barriers to entry for entrepreneurs to participate in this industry; yet if all of this was so, why were many more entrepreneurs not participating in and benefiting from this opportunity? Further exploration of the extant body of knowledge and discussions with entrepreneurs revealed that they find it difficult to convert their technical expertise into business solutions. They lack certain elements to do so. Initial enquiry suggests that the development agency as a custodian of business development should support this initiative. Finally, it raises the question whether the development agency knew how to assist entrepreneurs in this dynamic industry.
The research methodology approach is based on a sociotechnical research study and uses the concepts of Critical Realism Theory to provide a deeper consideration of the complexities involved in system development from a social and technical perspective. The study is based on the premise that in developing and using business model innovation, both social and technical aspects need to be considered.

This applied research study would specifically present a multi-factorial strategy model for enhanced mobile application development. It postulates that business model innovation can be used for business success by allowing people to collaborate. The focus of the research is about small business success and sustainability which ultimately contributes to the development of the SA economy.

The study would make use of current international studies, but be limited to mobile application development within the Western Cape.

\section{Research problem}

Not much attention has been given in the literature to the synergistic effects of disruptive innovation, business model innovation and development agencies for mobile application development SME success. The purpose of this study is, therefore, to explore the evolution of a multi-factorial strategy model to enable the development agency to be an augmenter in the commercialisation of the mobile applications development SME sector through business model innovation in response to disruptive innovation.

\section{Research questions}

How can a multi-factorial strategy model be evolved to enable the development agency to be an augmenter in the commercialisation of the mobile applications development SME sector through business model innovation in response to disruptive innovation?

\section{Research methods}

To increase the credibility and validity of the results, a variation of the Delphi research method was applied. Focused interviews took place to investigate, evaluate and produce suppositions about the innovation and technology industry. These were followed by an iterative process of collecting and filtering the judgements of industry experts by using a series of data collection and analysis techniques. The data were then analysed and another series of interviews took place with representatives of development agencies; these were based on the original round of interviews with industry. The combined feedback from industry as well as development agencies then fed into the multi-factorial strategy model.

It was envisaged that this applied research study would specifically present a model to capture the value of a multifactorial strategy model for enhanced mobile application development. It postulates that business model innovation can be used for business success to respond to disruptive 
innovation. The focus of the research is ultimately about small business success and sustainability that ultimately contributes to the development of the SA economy.

The study made use of current international studies, but was limited to mobile application development within the Western Cape.

The Critical Realist Enquiry was supported by the following:

- Structured real world...

- What are the key constructs in understanding the landscape?

- How does it extend the a priori model?

- Knowledge is socially produced...

- What, in your experience, are the salient business/ technological/political/social/market imperatives that inform the role of the development agent with respect to business model innovation and disruptive innovation?

- Critical discourse analysis...

- How can one explain the status quo?

- What are the successes and failures?

- What are the best practices?

- Emancipation agenda...

- What are the key issues to be addressed?

- What will it take to bring about the necessary changes that are indicated?

- Generative mechanisms...

- Why are things the way they are?

- Who/what holds sway?

- What are the critical performance underpinnings?

\section{The in-depth interview}

In the first phase of this study, a series of in-depth interviews were conducted with academics from the four universities in the Western Cape (Figure 2). The four academic institutions surveyed were the Cape Peninsula University of Technology, University of Cape Town, Stellenbosch University and the University of the Western Cape. The respondents were three academic members of staff from each of the respective IT departments in which software development was offered.

In a similar manner, phase 2 involved in-depth interviews with SMEs in the innovation and technology industry in and around Cape Town. The seven businesses interviewed consisted of four managing directors, one founder, one technical adviser and one senior applications developer.

The specific aim of these two phases was to determine the landscape of the mobile applications development industry in the Western Cape. This was achieved using a structured survey instrument using the dual media of personal and telephone engagement. The constraint on the sample size of the study was these businesses' availability for interviews. In hindsight of the views expressed by Boyce and Neale (2006), another advantage of the in-depth interview over the focus group is that it is extremely difficult to arrange a group session of business owners. They are busy people and the researcher

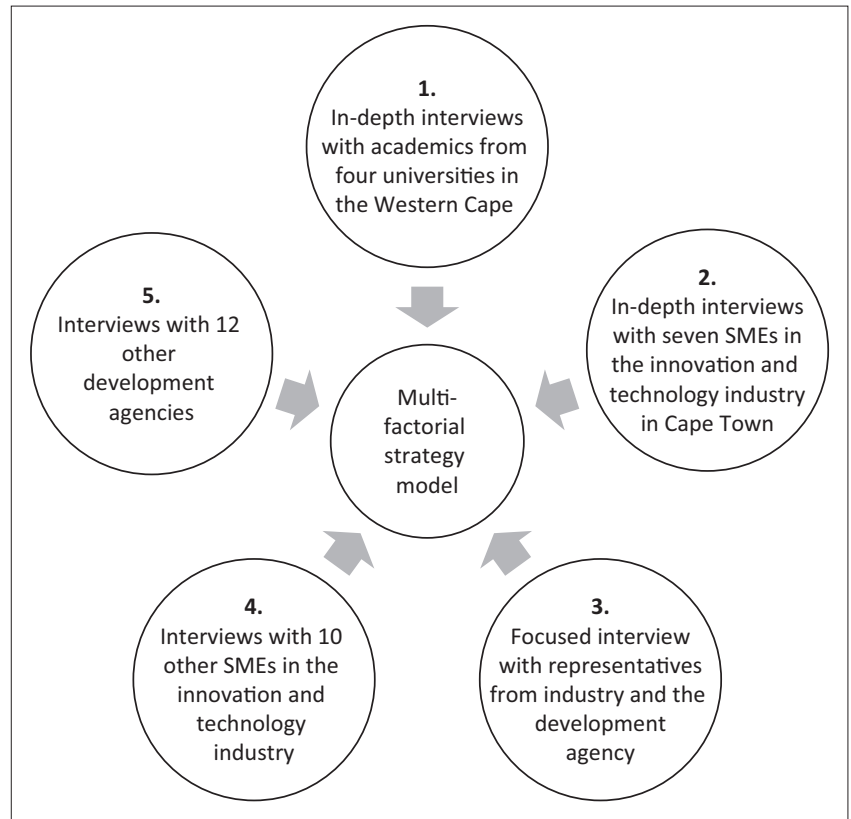

SMEs, small and medium-sized enterprises.

FIGURE 2: A graphical representation of the research design of this study.

is at the mercy of their availability. Owing to the relatively small sample size of the respondents, where the validity and reliability of the data could be questioned, the findings were interpreted from a qualitative rather than a quantitative perspective.

\section{The focused interview}

Millward (2004) states that the focused interview is also known as the focus group method, which is suitable for interviews of both individuals and groups. In keeping with the benefits of the focused interview as proposed by Millward (2004), phase 3 of this study involved a focused interview with representatives from industry and the development agency. The explicit objective was to test the findings of the empirical work conducted in phase 1 and to triangulate this with the findings that had emanated from the literature study, namely to interrogate the synergistic relationship between the development agency, disruptive innovation and business model innovation.

The following open-ended questions were posed to the representatives:

- What is the nature of disruptive innovation and is this indeed a common term used by industry or the development agency?

- What are the dimensions of business model innovation as understood by industry and the development agency?

- What is the role of the development agency in this industry?

Based on the responses from the focused interview, an interview schedule was constructed for phase 4 of this study, which was to interrogate 10 other SMEs in the innovation and technology industry. The in-depth interviews were recorded and the transcripts were analysed. The results were 
triangulated with the results of phase 2. Based on this, an interview schedule was constructed for phase 5 of this study, which involved the interrogation of 12 development agencies. The in-depth interviews were recorded and the transcripts were analysed.

\section{Sampling method}

The empirical work of this qualitative study involved five phases of interviews involving professionals in the business world.

Various methods can be used for sampling and the method used in this study was the stratified random sampling method. In this case, the population was divided into two strata based on the members' shared attributes or characteristics, namely the entrepreneurs and the development agencies. A random sample from each stratum was taken in a number proportional to the stratum's size when compared to the population. These subsets of the strata were then pooled to form a random sample. The individuals were then randomly chosen from these two strata. This method was selected to ensure diversity among the respondents and to ensure each one had an equal chance of being selected. The reason random stratified sampling was chosen is that it captures crucial population physiognomies in the sample that are proportional to the innovation and technology industry. The innovation and technology industry is also representative of a myriad of attributes, which makes stratified random sampling a suitable method.

The qualitative data received from the interviews were analysed and interpreted by making use of the content analysis approach recommended by Taylor-Powell and Renner (2003). The analysis process entailed getting to know the data, focusing on the analysis, categorising the information, identifying patterns and interpreting the data.

\section{Ethical considerations}

This study acknowledges that the ethics of business and research constitutes an area in which the role of values in the research process is a cause for concern. Confidentiality with respect to the sample of respondents (the SMEs and development agencies) who were interviewed was guaranteed by not divulging details of their respective businesses. The necessary written permission was obtained from them or from a senior member of staff (if and where necessary) in the organisation. Formal ethics approval to conduct the research was obtained from the Faculty's Research Ethics Committee at the Cape Peninsula University of Technology. All interviews and focus group sessions were scheduled at the convenience of the participants, and prior approval was obtained to record the interviews.

\section{Findings and interpretations Findings and interpretations of phases 1 and 2 of the study}

The following key findings relating to the way in which SMEs in this industry conduct their business manifested from the study:
- The majority of the businesses acknowledged the business potential of mobile application development.

- All the businesses, excepting one, expressed the importance of a model that could provide a strategy for the enhanced commercialisation of mobile applications development.

- Those involved with mobile application development require the model to assist them with revenue generation once the application has been completed. The needs of those businesses not involved with mobile application development are far more intense and involve the full spectrum from initiation through to commercialisation of the application. These businesses have expressed the importance of their being unable to take risks without a model that can help them to minimise these risks by providing them with clear guidelines, trends, technologies, skills, marketing and so on, relating to mobile applications.

The above-mentioned findings led to the following interpretations:

- The application development businesses acknowledged the potential in mobile applications but appeared to have difficulty in commercialising these applications. Further research is warranted around the establishment of a model that can provide a strategy for the enhanced commercialisation of mobile application development to assist businesses in mobile application development. This model will have to address a number of concerns, depending on the propensity of the business towards mobile application development. Research into what adjustments to the current business models of these businesses are required to enter into mobile application development is also recommended.

\section{Findings and interpretations of phase 3 of the study}

The following key findings and interpretations emanated from the focused interviews with representatives from industry and the development agency:

- A synergistic relationship appears to exist between development agency, disruptive innovation and business model innovation. In attempting to understand this synergistic relationship, it is essential to understand what the nature of disruptive innovation is and whether this is indeed a common term used by industry or development agencies.

- Interpretation: It appears that disruptive innovation is not a common term used by either industry or development agencies as stakeholders in the business development space.

- Reflection: How would the nature of disruptive innovation be made known to the stakeholders?

- It is important to understand what the dimensions of business model innovation are as understood by industry and the development agency. South African businesses and particularly small businesses are generally not big players in innovation. The answer to this philosophy 
might lie in the cultural, socio-political development, isolation and consolidation of large monopolies within SA. South African businesses tend to be conservative and follow international trends with regard to innovation and technologies.

- Interpretation: It appears that there does not appear to be a huge appetite for innovation within South African businesses. It is agreed that this is not the desirable state and the change imperatives need to be unpacked in order to resolve this condition of technology adoption to technology innovation.

- Reflection: Does this conservative business practice mean that there are evolutionary rather than revolutionary approaches towards innovation?

- The potential role of development agency was interrogated. Corporates dominate the innovation space and this lies in the legacy of South African society, its commerce and industry. Access to finance and the commercialisation of opportunity hinder innovation from the SME. Further elaboration is required on the concept of sustainability as it relates to innovation by highlighting the stages of development of an idea through to commercialisation and how the environment impacts on the ability of the technology entrepreneur to survive and thrive. The agency will have to deal with young entrepreneurs' naivety about appropriate research on and business models for their innovations. Higher education institutions have a role to play.

- Interpretation: It appears that higher education institutions should also understand their importance as a development agency in the innovation space because a strong focus on research and development is essential for the sustainability of the entrepreneur.

- Reflection: What role should higher education institutions play in this regard?

- In interrogating the mobile application development application landscape, it is important to understand what the key constructs are. Role models within the application of technology will serve as a good mentoring process for entrepreneurs in this space. Small and medium-sized enterprises can compete on a technological but not on a commercial level with corporates. Corporates have a very strong monopoly, but SMEs engage to a limited extent. Small and medium-sized enterprises are poor researchers of real business opportunities, whereas corporates tend to be more meticulous and follow global standards. The innovation resorts at the SME, but corporates have the ability to commercialise the innovation. Corporates who participate do so in support of their ambition, and mission and vision. Small and medium-sized enterprises, on the other hand, do not always clearly know how they should participate and often do so because of social entrepreneurship or simply to dabble in entrepreneurship. They often participate with no real viability study on the application and no real business model with respect to the application. There appears to be the tendency that if we build it, they will buy it'. They participate as isolated entities and there is no real serious evidence of networking and collaboration. There is a good enabling environment in SA by way of the existing infrastructure partners which is superior to the rest of Africa. This is critical to the rollout of any mobile application. This infrastructure sets the scene for the players in this space. The rest of Africa tends to look at lower level mobile interaction via SMS as opposed to bandwidth-intensive mobile applications which require more data interchange. There is a low smartphone penetration in the rest of Africa, with a larger functional phone concentration. The younger players (entrepreneurs) use their personal experience and their 'pain', 'itch', 'issue' as a driver for their mobile application development. The more experienced entrepreneurs use the established business models, larger problems, systems and global issues as their points of departure. Very few entrepreneurs come with well-researched opportunities as their starting point for any business venture, whereas corporate opportunities are driven by their business vision.

- Interpretation: It appears that South African businesses are followers and they benchmark to a minimum standard of global compliance. Consequently, these businesses are not really innovators but implementers of technology. The role players are playing with all technologies that are available. They are not sensitive to national boundaries and are willing to do business at a continental level if required. They are playing first and foremost for money but also for personal needs and interests.

- Reflection: Could this status quo be because SMEs are scared to reveal too much to their competitors and associated role players, and lose out on the opportunity?

- The following themes were confirmed in the focused interviews to be all-inclusive of the functions of development agency as they address the start-up, environment and on-going concerns of the SME:

- strategic support

- promotion of opportunity

- capacity building

- growth and sustainability.

The following categories of the way in which SMEs in this industry conduct their business have manifested from the focused interviews:

- Business model: SMEs appear to have a vague understanding of their business functions and value chain and how their businesses expect to generate income.

- Business opportunity: SMEs appear to have a need for assistance with a suitable or constructive opportunity to generate income for their businesses.

- Technology platform: SMEs appear to have adopted a base to create their products and services that support their existing needs. This technological base delivers their products without their having to establish a new process / technology.

- Market trends: SMEs appear to be following the general direction, inclination and preference in which their industry is moving. They, therefore, lean towards being followers of their industry rather than leaders. 
- Product expertise: SMEs appear to have been established based on the business owners' deep technical understanding of their product and associated technologies.

- Service expertise: SMEs appear to be operating based on the business owners' understanding and experience acquired before establishing the business.

\section{Findings and interpretations of phase 4 of the study}

The following key findings and interpretations emanated from the in-depth interviews with 10 other SMEs in the innovation and technology industry:

- Disruptive innovation is not a common term used in industry.

- The nature of disruptive innovation requires thinking 'outside the box' and a change in management style.

- The dimensions of business model innovation are:

- about looking at innovation as something that has to be done and that can be done depending on the status of the business

- a reflection of the innovativeness of the actual business model and one which that show some form of innovation or sustainability for going forward

- how someone in business can change their business model as innovation takes place

- the constant recreation of the way businesses operate, inter alia, sharing ideas and operating in a different manner from the established norms to improve the business

- about reinventing the business model around client needs.

- The role of the development agency in the innovation and technology industry is to:

- provide access (in its broadest sense) for businesses

- provide business support at various levels

- navigate the difficult administrative avenues for the business

- assist with financial planning and management

- provide business skills

- indicate industry trends.

- All of the SMEs agreed that it was crucial for a business to be responsive to unpredictable and disruptive market forces.

- Nine of the 10 SMEs agreed that it was crucial for a business to turn an innovation into a business that could succeed and so ensure its long-term sustainability.

- Nine of the 10 SMEs agreed that it was crucial for a business to take a new technological solution from a real or perceived need and to develop this technology into a viable entity by introducing it to the market.

- Nine of the 10 SMEs agreed that it was crucial for a business to have a proactive approach to the marketplace when it believed that market interests in its offering were low or dwindling.

- Eight of the 10 SMEs agreed that it was crucial for a business to pursue the research and development of new products to ensure its sustainability.
- All of the SMEs agreed that it was crucial for a business to interrogate the ways in which it conducted its business to enhance its service offering.

- The following dominant themes represent the assistance that SMEs in this industry require from the development agency:

- strategic support

- capacity building

- promotion of opportunity

- growth and sustainability.

These themes show a direct correlation with the literature study and with those confirmed in the focused interview to be all-inclusive of the functions of development agency as they address the start-up, environment and on-going concern of the SME.

\section{Findings and interpretations of phase 5 of the study}

The following key findings and interpretations emanated from the in-depth interviews with development agencies:

- The following themes were identified by development agencies describing how SMEs in this industry conduct their business:

- static business model

- venture participation

- technology acquisition

- market access and penetration

- product adaptation

- service adaptation.

- The following categories were identified by development agencies describing the assistance required from SMEs in this industry:

- Agile business model: Market conditions are in a state of fluctuation, and clients are candid about their expectations. Small and medium-sized enterprises should, therefore, adopt an agile approach which is more interested in interactions than processes and in arriving at solutions. It is more collaborative which means that the business can be more responsive to change.

- Venture creation: SMEs should embark on the process of transforming a new idea or technology into a business that can succeed and will attract business interest.

- Technology innovation: As opposed to the adoption of externally developed technologies, SMEs are urged to develop and use technology in new ways, where the result is a more efficient business and an improved alignment between technology initiatives and business goals.

- Market creation: SMEs are challenged to take a proactive approach to the marketplace when they believe that market interest in their offerings is low, existing competitors too strongly entrenched or customers too few. They should deliberately 
develop a new product or service that is more useful, affordable or better than those of existing role players in the market.

- Product innovation: SMEs are challenged to create and subsequently introduce a product or service that is either new or improved. This innovation could include changes in the design of established products or the use of new materials or components in the manufacture of established products.

- Service innovation: SMEs should have the courage to develop a new or significantly improved service concept that benefits themselves as well as their customers. This should improve their competitive edge. It could be a service product or service process that is based on some technology or systematic method.

The themes align with the views of Rogers (2003) who proposes that Diffusion of Innovation implies that the adoption of innovation does not only rely on the innovation's technical capabilities. They should consider how its business model relates to the particular segment of the market to which its innovation is appealing.

\section{Summary of the findings}

The findings and interpretations of this critical realist study revealed a structured real world of the landscape of mobile application development in the Western Cape, SA, by identifying its key constructs. It then revealed that knowledge is socially produced by identifying the salient imperatives that inform the role of the development agent with respect to business model innovation and disruptive innovation. By means of critical discourse analysis of the views expressed by the respondents, it revealed the emancipation agenda of mobile application development in the Western Cape, SA. In doing so it also ultimately uncovered the generative mechanisms in understanding, among others, what the critical performance underpinnings are.

\section{The Disruptive Innovation State Response Model}

Key to this study is the notion of technology transfer and technology commercialisation. The study suggested that a multi-factorial strategy model could be evolved to enable the development agency to be an augmenter in the commercialisation of the mobile applications development SME sector through business model innovation in response to disruptive innovation. Based on the approbation of the value of models from Dumanski and Pieri (1995), Gauthier and Lardic (2003), Linster (2003), Shoemaker, Tankard and Lasorsa (2004) and Sidora-Arcoleo et al. (2012), a particular multi-factorial strategy model was developed for this study.

The findings indicated that it is important to understand what the dimensions of business model innovation are as understood by industry and development agency. It appears that there does not appear to be a huge appetite for innovation within South African businesses. It is agreed that this is not a desirable state and change imperatives need to be unpacked to resolve this condition of technology adoption to technology innovation. The responses of the focused interview depicting the role of the development agency in the innovation and technology industry suggest that the development agency will also have to deal with the young entrepreneurs' naivety about appropriate research on and business models of their innovations. Corporates tend to dominate the innovation space and this lies in the legacy of South African society, its commerce and industry. Access to finance and the commercialisation of the opportunity hinders innovation from the SME. Further elaboration on the concept of sustainability as it relates to innovation is needed by highlighting the stages of development of an idea through to commercialisation and how the environment impacts on the ability of the technology entrepreneur to survive and thrive.

In consideration of these facts and the rest of the results depicted, this multi-factorial strategy model has ultimately manifested in the form of the Disruptive Innovation State Response Model (Figure 3).

In its simplest form, the Disruptive Innovation State Response Model proposes two states, namely the condition of the company and the provision that is required to respond to the disruptive innovation. It can also be known as a ConditionProvision Model, which at its core proposes that development agency is the link between these two states. Essentially, the model proposes that a disruptive innovation presents the company with a particular condition, to which the provision of the company should be the process of business model innovation.

The great tension is disruptive innovation which the company experiences whether by default or by design. There are two aspects of the condition, namely a perceived opportunity or a perceived threat. This is determined by the structural imperatives within the company. If the company lacks certain structural imperatives, then the disruptive innovation will present a threat. If the company has sound structural imperatives in place, then the disruptive innovation could present itself as an opportunity.

In understanding its role, the development agency should resolve the industry culture and dynamics to offer a template for action for the company. It is the industry culture, after all, that provides the context for business meanings while, at the same time, also being influenced by these business meanings.

Similar to the condition, there are two aspects of the provision: a company response and an industry response. The appropriate response is determined by agency which refers to the capacity of the company to act independently and to make its own free choices in creating solutions for business 


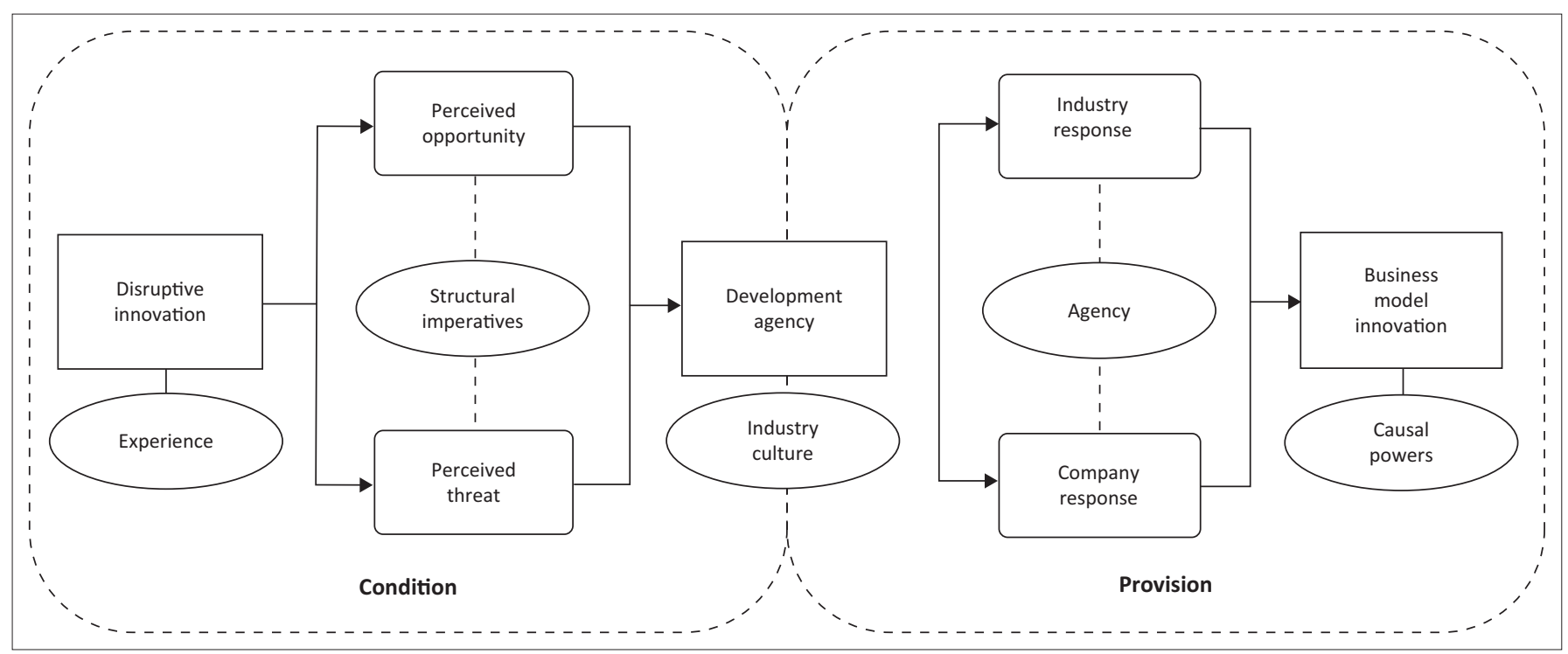

FIGURE 3: The Disruptive Innovation State Response Model.

problems. The company response may simply be the need to address an internal operation or system to respond to the disruptive innovation. On the other hand, the company may be required to pursue assistance outside of the organisation to respond to the disruptive innovation.

As an industry response, agency recognises that disruptive innovation challenges, for instance, a company's configuration in the way that the business can respond to the disruptive innovation. If there is a reform that is required, the configuration of the business needs to be investigated, but the provision will lie in the network of the business. This network could constitute collaboration with competitors. This can mean that a small business may have to partner with a medium-sized business. In this way, the business can maintain its status quo and not lose out to competitors.

Alternatively, the company might find itself in a state where all its competitors are fighting and are in a general restructuring state. This calls for a radical shift in which the business has to do extraordinary things. The condition that is called for is agility, and the provision is innovation. In this way, the business could achieve market penetration in the industry.

\section{Managerial implications}

Ultimately, the Disruptive Innovation State Response Model proposes that the company experiences disruptive innovation at different intensities because of different causal powers. It recognises that causes essentially generate effects and that generative relations are a set of causal roles that are involved in the generation of effects. In so doing, the model proposes that the antidote to disruption (technical) must be progressive management by way of business model innovation (social). So, the antidote to disruptive innovation is a management response; however, this must be understood across the industry in which the study is undertaken. What is required from management is that it needs to bring about a paradigm shift in the way that the whole notion of a business is remodelled.

\section{Limitation of the study}

The specific nature of empirical research methods could result in potential limitations to the generalisability of the results. This should be considered before generalising the results beyond the precise categories of SMEs who have participated in the study. The SMEs were essentially black and male business owners, drawn from the formal economy and located within the Cape Metropole, which could give rise to a potential sample bias. A potential non-response bias might, therefore, exist because responses from SMEs from the extended Western Cape and rural surrounds could be different from those of the current respondents.

\section{Further research}

To demonstrate the generalisability of the results of this study, future studies should, therefore, have a larger and more geographically spread sample as well as a more even distribution of male and female as well as white and black SMEs. Future studies could also involve the application of the Condition-Provision Model, which is integral to the Disruptive Innovation State Response Model, to other sectors beyond the realm of the technology sector.

\section{Conclusion}

This study explored the landscape for mobile application development in the Western Cape, SA, and the role of the development agency in attempting to promote mobile application development entrepreneurs' success and sustainability which ultimately contributes to the development of the SA economy. The social arena of this study revolved around alleviating poverty and economic inequality. The technology arena, in contrast, is the focus on mobile applications. Key to this study is the notion of 
technology transfer and technology commercialisation, where through a multi-factorial approach the development agency is equipped with a Disruptive Innovation State Response Model that will assist them in supporting mobile application development entrepreneurs towards enhanced competitiveness that could assist in alleviating poverty and reducing economic inequality.

\section{Acknowledgements}

This article is the product of a doctoral thesis and Mr E. Francke is the student (principal researcher) with Prof. B. Alexander as the supervisor of the original study.

The views expressed in this article are the views of the authors and not an official position of any institution or funder.

\section{Competing interests}

The authors declare that they have no financial or personal relationships that may have inappropriately influenced them in writing this article.

\section{Authors' contributions}

B.A. was the project leader and was responsible for the project design and conceptual contributions. E.F. performed the literature study, interviews, analysis and conclusions. Both authors co-wrote the manuscript.

\section{References}

Ammar, O. \& Ouakouak, M.L., 2015, 'The business model as a configuration of value: Toward a unified conception', Journal of Business and Management Sciences 3(2), 78-84.

Baden-Fuller, C. \& Haefliger, S., 2013, 'Business models and technological innovation', Long Range Planning 46(6), 419-426.

Bankole, F.O. \& Bankole, O.O., 2017, 'The effects of cultural dimension on ICT innovation: Empirical analysis of mobile phone services', Telematics and Informatics 34(2), 490-505. https://doi.org/10.1016/j.tele.2016.08.004

Bower, J.L. \& Christensen, C.M., 1995, 'Disruptive technologies: Catching the wave', Harvard Business Review 73(1), 43-53.

Boyce, C. \& Neale, P., 2006, Conducting in-depth interviews: A guide for designing and conducting in-depth interviews for evaluation input, Pathfinder International, Watertown, MA

Díaz-Díaz, R., Muñoz, L. \& Pérez-González, D., 2017, ‘The business model evaluation tool for smart cities: Application to SmartSantander use cases', Energies 10, 262. https://doi.org/10.3390/en10030262

Dumanski, J. \& Pieri, C., 1995, Application of the pressure-state-response framework for the land quality indicators (LQI) programme, Food and Agriculture Organization of the United Nations, Rome, viewed 03 February 2015, from http://www.fao. org/docrep/w4745e/w4745e08.htm

Francke, E. \& Alexander, B., 2012, 'Innovative business models: The ambush of disruptive technologies on business', paper presented at the 2nd Design, Development and Research (DDR) conference, Bellville, 3-5th September.

Gartner, 2008, Gartner identifies top ten disruptive technologies for 2008 to 2012, viewed 12 April 2012, from http://www.gartner.com/it/page.jsp?id=681107\#_ftn1

Gartner, 2014, Gartner says less than 0.01 percent of consumer mobile apps will be considered a success by their developers through 2018, viewed 20 April 2014, from http://www.gartner.com/newsroom/id/2648515
Gauthier, C. \& Lardic, S., 2003, 'Un modèle multifactoriel des spreads de crédit: Estimation sur panels complets et incomplets [A multifactorial model of credit spreads: An estimation using complete and incomplete panels]', Economie \& Spreads: An estimation using complete and incomplete panels]',
Prévision 159(3), 53-69. https://doi.org/10.3406/ecop.2003.6912

Institute of Directors in Southern Africa, 2002, King report on corporate governance for South Africa 2002, South Africa, viewed 20 August 2018, from https://www. saica.co.za/Technical/LegalandGovernance/King/tabid/2938/language/en-ZA/ Default.aspx

Institute of Directors in Southern Africa, 2016, King report on corporate governance for South Africa 2016, South Africa, viewed 20 August 2018, from https://www. iodsa.co.za/page/KingIVReport

Krugman, P., 1994, 'Competitiveness: A dangerous obsession', Foreign Affairs 73(2), 28-44. https://doi.org/10.2307/20045917

Le Roux, W.J.L., 2010, 'Collaborative business models: Enabling enterprise development in the tourism and hospitality industry', unpublished bachelor of industrial and systems engineering thesis, University of Pretoria, South Africa.

Linster, M., 2003, OECD environmental indicators: Development, measurement and use, OECD, Paris, viewed 10 January 2017, from https://www.oecd.org/env/ indicators-modelling-outlooks/24993546.pdf

Mandel, M., 2012, Where the jobs are: The app economy, viewed 20 February 2014, from http://www.technet.org/wp-content/uploads/2012/02/TechNet-App-Economy-JobsStudy.pdf

Millward, L., 2004, 'Focused interviews', in M.S. Lewis-Beck, A. Bryman \& T.F. Liao (eds.), Sage encyclopedia of social science research methods, pp. 396-397, Sage, Thousand Oaks, CA.

Naidoo, R., 2002, Corporate governance: An essential guide for South African companies, SmartSantander Juta and Company Ltd., Cape Town, ISBN 1919930086, 9781919930084

Neneh, B.N. \& Van Zyl, J., 2014, 'Growth intention and its impact on business growth amongst SMEs in South Africa', Mediterranean Journal of Social Sciences 5(20), 172-183. https://doi.org/10.5901/mjss.2014.v5n20p172

Olawale, F. \& Garwe, D., 2010, 'Obstacles to the growth of new SMEs in South Africa: A principal component analysis approach', African Journal of Business Management 4(5), 729-738.

Organisation for Economic Co-operation and Development (OECD), 2017 'OECD economic surveys: South Africa', viewed 03 January 2018, from https://www. oecd.org/eco/surveys/2017-OECD-Economic-Survey-South-Africaoverview-2017.pdf

Osterwalder, A., 2004, 'The business model ontology: A proposition in a design science approach', unpublished doctoral thesis, University of Lausanne, Switzerland.

Porter, M.E., 1990, The competitive advantage of nations, Free Press, New York.

Porter, M.E., 1998, 'Clusters and the new economics of competition', Harvard Business Review 76(6), 77-90.

Porter, M.E., 2001, 'Strategy and the Internet', Harvard Business Review 79(3), 62-78.

Rakestraw, T.L., Eunni, R.V. \& Kasuganti, R.R., 2013, 'The mobile apps industry: A case study', Journal of Business Cases and Application 9, 1-26.

Robson, P. \& Bennett, R., 2000, 'SME growth: The relationship with business advice and external collaboration', Small Business Economics 15(3), 193-208. https://doi. org/10.1023/A:1008129012953

Rogers, E., 2003, Diffusion of innovations, 5th edn., Free Press, New York.

Rowlands, S., 2013, Over 160 billion consumer apps to be downloaded in 2017, driven by free-to-play games, viewed 13 February 2015, from https://www. juniperresearch.com/press-release/apps-and-app-stores-pr1

SBP, 2011, Priming the soil: Small business in South Africa, headline report of SBP's SME growth index ${ }^{\mathrm{TM}}$, SBP, Johannesburg, viewed 22 March 2014, from http:// www.sbp.org.za/uploads/media/SBP_SME_Growth_Index Headline Report November_2011_01.pdf

SBP, 2015, SBP alert: 2015 SME growth index headline results, SBP, Johannesburg, Bulletin 2, viewed 22 December 2015, from http://www.sbp.org.za/uploads/ media/SBP_Alert_2015_SME_Growth_Index_Headline_Results.pdf

Schumpeter, J.A., 1947, 'The creative response in economic history', Journal of Economic History 7(2), 149-159. https://doi.org/10.1017/S0022050700054279

Shoemaker, P.J., Tankard, J.W. \& Lasorsa, D.L., 2004, How to build social science theories, Sage, Thousand Oaks, CA.

Sidora-Arcoleo, K., Feldman, J.M., Serebrisky, D. \& Spray, A., 2012, 'A multi-factorial model for examining racial and ethnic disparities in acute asthma visits by model for examining racial and ethnic disparities in acute asthma visits by
children', Annals of Behavioral Medicine 43(1), 15-28. https://doi.org/10.1007/ children', Annals of
s12160-011-9328-3

Taylor-Powell, E. \& Renner, M., 2003, Analyzing qualitative data, University of Wisconsin, Madison, WI, Cooperative Extension Publishing Operations, viewed 17 April 2016, from https://learningstore.uwex.edu/assets/pdfs/g3658-12.pdf 